\title{
Non-Linguistic Variables as Predictors of Students Performance in French Language in Calabar Education Zone, Cross River State, Nigeria
}

\author{
Agbor, Catherine Alex (Phd) \\ Arts Education Department, University Of Calabar, Calabar, Nigeria \\ Ogar, Kanebe Nsor \\ Arts Education Department, University Of Calabar, Calabar, Nigeria
}

\begin{abstract}
This study aimed at examining non-linguistic variables as predictors of students' performance in French language in Calabar education zone of Cross River State, Nigeria. Two sub-variables: school supportiveness and home supportiveness were used to formulate the hypotheses for the study. Survey research design was adopted for the study while the simple random, proportionate and purposive sampling techniques were used to select 288 junior secondary school three students from 7 public secondary schools in the zone. Non-linguistic variables questionnaire (NLVQ) and French language Performance Test (PLLT) were the instruments used for data collection. The simple linear regression was the statistical technique adopted to test the hypotheses at 0.05 level of significance. The results revealed that school supportiveness can significantly predict students' performance in French language while home supportiveness did not predict performance in French language. From the findings of the study, conclusion was drawn and recommendation proffered.
\end{abstract}

Keywords: Calabar education zone, non-linguistic variables, school supportiveness, home supportiveness

DOI: $10.7176 / \mathrm{JEP} / 10-8-04$

Publication date:March $31^{\text {st }} 2019$

\section{Introduction}

The Calabar education zone is one of the three (3) education zones in Cross River State of Nigeria. It is made up of seven (7) Local Government areas comprising Akamkpa, Akpabuyo, Bakassi, Biase, Calabar Municipality, Calabar South and Odukpani Local Government Areas. The education zone is composed of two major ethnic groups, the Efiks and the Ejaghams. English Language, Efik and Ejagham are the dominantly spoken languages.

The people of the study area are predominantly farmers, traders, fishermen, craftsmen, gold smith with the urban areas mostly inhabited by civil/public servants. The basic agricultural deposits in the area are; Cocoa, oil palm, cassava, timber and vegetables, all of these produced in both domestic and commercial quantities for consumption as well as for export. Also, mineral resources such as; limestone, granite and crude oil is extracted from the area.

The education zone has 81 registered public secondary schools with numerous privately owned and missionary schools to compliment the number of public secondary schools. One federal university (The University of Calabar), one state owned University (Cross River University of Technology); one privately owned university (Arthur Javis University); two state colleges: College of Education Akamkpa and Cross River State College of Health Technology, Calabar. Other important institutions located in the study area include; the Nigerian Ports Authority (NPA), the Export Processing (Free Trade) Zone (EPZ), several standard hotels and the famous Tinapa Resort lies to the North of the city beside the Calabar Free Trade Zone.

The area also boasts of eye catching natural tourism base, with international reputation like; the National Museum, a slave history Museum, the Drill Monkey Park and large forest reserve. The Cross River State Annual Christmas Festival held every year within the study area, attracts thousands within and outside Nigeria. The Festival which include; musical performance from both local and international artists, the annual Calabar Carnival, Boat regatta, fashion shows, Christmas village, traditional dances, the bikers carnival and the annual Ekpe festival are yearly events that bring in thousands of tourist from all over the world during the yuletide season. French Language contact is prevalent in the border towns of Amana, Ikang and Ikom and also in schools and the French Language centre in Calabar.

Performance is the yardstick for determining the successes and failures of an educational programme and education is basically associated with learning, skill acquisition, knowledge orientation/reorientation among others. Education is a medium of instruction and an instrument for national development (FRN 2004). It seeks the emancipation of any given society and promotes better human relationship at all spheres. The achievement of educational objectives is of great importance to government, schools, parents, students and researchers in the educational sector.

Language is a major tool for the attainment of educational objectives. Its importance cannot be undermined 
because apart from it being a subject (Language education) in the school curriculum, it also plays the all-important role of medium of instruction (Language in education). Language is man's channel of communication; it is the human capacity for acquiring and using complex systems of utterance. Wibowo (2001) defined language as a system of symbols that are meaningful and can articulate sounds (generated by said tools) which are arbitrary and conventional and used as a means of communication by a group of humans to give birth to feelings and thoughts. Uwatt (2015) stated that the purpose of language is to provide the physical and notional frame for thought forms as well as their conversion into expressive communication patterns.

Human language is unique among the life forms on earth because its complex structure affords a much wider range of possible expressions and uses than any known system of animal communication. It is still impossible to ascertain the numbers of languages in the world because while more languages are developing others are facing extinction. For instance, about three hundred (300) languages are seriously endangered or on the verge of complete extinction (UNESCO, 1996) and linguists are yet to differentiate between distinct languages and dialects however, Simons and Charles (2018) estimated about 6,909 distinct languages. With this number, it is impossible for a person to have the ability to speak all languages. Li and Dan (2006) are of the opinion that, the human race needs a common and identifiable language for communication, this too is yet to be achieved. The near solution on ground is the ability to communicate in two or more languages (bi/multilingualism).

Nigeria, known to many as the giant of Africa is a country unique in its diversity of nations, peoples and cultures. It is the most populous black nation, with a population of over 170 million people and about 526 languages (Simons and Charles, 2018). For easy communication amongst Nigerians, English Language was adopted as Nigeria's first official language owing to its British colonisation.

Nigeria is an anglophone country surrounded by francophone countries, to the North East it has Chad, North West Niger, South West by Benin and South East Cameroon, these may have prompted Onyemelukwe and AdieOffiong in Kolawole (2015) to describe Nigeria as an anglophone country in a sea of francophone. For easy communication with its neighbours, Nigeria in 1996 adopted French Language as its second official language. The National Policy on Education (FRN 2004: 10) stated that "for smooth interaction with our neighbours, it is desirable for every Nigerian to speak French Language. Accordingly, French shall be the second official language and it shall be compulsory in primary and junior secondary schools". This pronouncement signals the need for bi/multilingualism in Nigeria.

Citizens of countries with two or more official languages example Canada, Malta and New Mexico can communicate in languages so adopted and enjoy the advantages of being at home in countries where such languages are spoken. The importance of bilingualism or multilingualism cannot be over emphasized in today's $21^{\text {st }}$ century of globalization, its benefits to Nigerians is not only limited to communication with neighbours, but cuts across education and residency. Nigerians who wish to study or reside in francophone countries would not be limited by language. Also, others in need of medical tourism or other forms of tourism can do so without an interpreter in francophone countries. Trade (buying and selling) is also an added advantage. Job opportunities seems available for individuals with ability to communicate in more than one international language especially in some organisations like, The United Nations Organization (UNO), African Union (AU), Economic Community of West African States, Organization of Petroleum Exporting States among others.

The benefits associated with the ability to speak more than one official language should intensify the yearning of Nigerians to acquire French Language, but the reverse is the case, as most secondary school students who are taught the language are yet to demonstrate ability to speak nor write in French Language after 22 years of its adoption as second official language. French Language as Nigeria's second official language is obtainable only on paper. The machineries necessary for its achievements are yet to be put on ground, in places where they are found, they are undermanaged, mismanaged or totally not in use (Kolawole 2015).

Results of the negligence of French Language can be seen on students' poor performance in French Language. For instance, statistics in the following years 2010 to 2015 in French Language at the Cross-River State Basic Education Certificate Examination (BECE), showed performance to be poor and continually so for years (see appendix I). Many of our students after going through Colleges of Education, do not possess the linguistic competence needed to pass O' levels French Language unaided (Kolawole, 2015).

The problems associated with the teaching and learning of French Language ranges from less lecture time allocation to dearth of course materials, poor infrastructure, inadequate teaching/learning materials, poor power supply, manpower deficiency among others (Ayeomoni, and Igonor, in Kolawole 2015).

Researches have been carried out to proffer solutions to the problem of poor performance in French Language: (Agbor, 2001), (Ogar, 2012), (Eton, 2015) and (Ayeni, 2012). Government on its part has done much to support and encourage the teaching/learning of French language. In the National Policy on Education, FRN (2004) French Language was pronounced second official language and made compulsory in primary and junior secondary schools. The National Commission for Colleges of Education (NCCE) and the National Universities Commission are put in place by government to regulate and standardise the activities of colleges and universities thereby ensuring the production of suitable and qualified teachers. It has also established the Nigerian French Language Village in 
Badagry, Lagos state. There exists a scholarship scheme by government in support of French language students. Government has also made sure that its secondary schools have qualified teachers. In spite of all these efforts, recorded achievement so far is just the tip of the iceberg.

Chomsky (2006) is of the opinion that performance in language occurs in real life situations, and it is subject to many non-linguistic influences. For example, distractions or memory limitations can affect lexical retrieval. Such non-linguistic factors are completely independent of the actual knowledge of language and established that speakers' knowledge of language is distinct from their actual use of language. Castro and Peck (2005) added that even students who do not appear to have any language-learning deficits, such as those who score highly in Language Aptitude Test (LAT), encounter difficulties in language classroom.

Gass and Selinka (2008) added that some individuals will outperform others in learning a new language. This according to them could be due to some non-language factors. In addition, the notion of learner-centred instruction in foreign and second languages grew out of the recognition that language learners are diverse in their reasons for learning another language, their approaches to learning, and their abilities (Wenden, 2002).

From the foregoing, factors affecting language learning could be linguistic based; bothering on the rules or methods associated with language learning or simply put; language-based factors, non-linguistic based; bothering on social and environmental conditions.

Considering other research works, less concentration has been invested on the impact of these non-linguistics variables: school supportiveness and home supportiveness in the research area. Therefore, this research work is interested in finding out if these variables could predict performance of students' in French language in Calabar education zone of Cross River State, Nigeria.

\section{Problem statement}

Countries with two or more official languages have their citizenry possessing a good command of all official languages or a good command of one and the ability to dabble in the other(s). For about 22 years now, French language was given the status of second official language in Nigeria, but the reality on ground is disheartening as majority of Nigerians find it difficult to achieve the basics (salutation, presentation or even simple conversation) in the language.

The school which is supposed to be an agent for the attainment of such national objectives has failed as performance in most examinations show a downward toll. Some people have attributed this to many factors such as; lack of qualified teachers, availability of teaching learning aids, period allocation on the time table, pedagogy amongst others.

Language learning occurs in real life situations and is determined by both linguistic and non-linguistic factors. It is of interest to the researcher to establish if these non-linguistic variables such as: school supportiveness and home supportiveness are significant predictors of students' performance in French Language in Calabar education zone.

\section{Purpose of study}

The main purpose of this study was to determine whether the non-linguistic variables can predict performance in French Language. Specifically, this study examined if:

1. School supportiveness predicts students' performance in French Language.

2. Home supportiveness predicts students' performance in French Language.

\section{Hypotheses}

The following null hypotheses were formulated to guide the study:

1. School supportiveness does not significantly predict students' performance in French Language.

2. Home supportiveness does not significantly predict students' performance in French Language.

\section{Methods and procedure}

The research design adopted for the study was the survey research design. The population of the study comprised all 6568 JSS III students in the 81 public (government owned) secondary schools in zone. Three sampling techniques (simple random, proportionate and purposive) were used to select the sample for this study. Simple Random Sampling Technique was applied to select four local government areas which are approximately 60 percent out of the seven local government areas that make up the Education Zone. In this case, the name of each local government was written on a piece of paper, folded and put in one basket. Thereafter, the researcher picked four papers from the basket which formed the sampled local government areas. This was done to ensure every Local Government Areas (LGA) had equal opportunity of being selected. The four selected LGAs were Calabar Municipality, Odukpani, Akamkpa and Calabar South.

Proportionate Sampling Technique was used to select $10 \%$ of schools in the selected LGAs. Ten percent of schools in the selected local government area were seven public secondary schools. Purposive sampling procedure 
was employed to select seven schools from these LGAs. The reason for this sampling procedure was to avoid selecting schools without French teachers at all three arms of JSS I, II and III. Purposive Sampling Procedure was also used to select a class (arm) of JSS III students from each selected school this is because only the JSS III class that were free at the time of data collection participated.

The sample for the study was 288 students, sampled from seven secondary schools in four Local Government Areas in the zone. Two instruments were employed by the researchers to gather relevant data for this study; NonLinguistic Variable Questionnaire (NLVQ) and French Language Performance Test (FLPT).

\section{Results}

The results of the analysis are presented hypothesis by hypothesis.

Hypothesis one: Simple linear regression was used to test this hypothesis at the 0.05 level of significance and the result is presented in Table 1.

TABLE 1

Regression Model Summary of school supportiveness and students' performance in French Language

\begin{tabular}{|c|c|c|c|c|c|}
\hline Model & $\mathrm{R}$ & R square & $\begin{array}{l}\text { Adjusted R } \\
\text { square }\end{array}$ & $\begin{array}{l}\text { Std error of } \\
\text { the estimate }\end{array}$ & \\
\hline 1 & 0.353 & 0.124 & 0.121 & 5.900 & \\
\hline Source of Variables & Sum of Squares & Df & Mean square & $\mathrm{F}$ & Sig. \\
\hline \multirow{5}{*}{$\begin{array}{l}\text { Regression } \\
\text { Residual } \\
\text { Total } \\
\text { Variables }\end{array}$} & 1165.776 & 1 & 1165.776 & $33.492 *$ & .000 \\
\hline & 8214.648 & 236 & 34.808 & & \\
\hline & 9380.424 & 237 & & & \\
\hline & Regression weight & & & & \\
\hline & -5 & Std error & $\begin{array}{l}\text { Standard. } \\
\text { Coef. }(\beta)\end{array}$ & t-value & Sig. \\
\hline (constant) & 0.412 & 2.185 & & 0.189 & .000 \\
\hline School supportiveness & 0.684 & 0.118 & .353 & 5.787 & $.000^{*}$ \\
\hline
\end{tabular}

The result in Table 1 shows that, there was a significant relationship $(\mathrm{R}=0.353)$ between school supportiveness and students' performance in French Language. Overall, the model accounts for $12.4 \%$ of the variance in students' performance in French Language and is a significant fit of the data.

Furthermore, the regression ANOVA revealed that, there was a moderate linear association (contribution) of school supportiveness to students' performance in French Language given by the F-ratio $(1,236)=33.492 ; p<$ 0.05 . The adjusted $R^{2}(0.124)$ shows some shrinkage of the unadjusted value $(0.121)$ indicating that the model could be generalized to the population. This is a positive relationship $(\beta=.353)$, given by the sign of the beta indicating that when students enjoy support from school, their performance in French Language increases. Finally, we could conclude that, school supportiveness predicts performance in French Language. This means that, the null hypothesis which stated that, school supportiveness does not significantly predict students' performance in French Language was rejected while the alternate hypothesis was retained. .

Hypothesis two: Simple linear regression was used to test this hypothesis and the result is presented in Table 2.

TABLE 2

Regression Model Summary of home supportiveness and students' performance in French Language

\begin{tabular}{|c|c|c|c|c|c|}
\hline Model & $\mathrm{R}$ & $\mathrm{R}$ square & $\begin{array}{l}\text { Adjusted R } \\
\text { square }\end{array}$ & $\begin{array}{c}\text { Std error of } \\
\text { the } \\
\text { estimate }\end{array}$ & \\
\hline 1 & 0.027 & 0.001 & 0.004 & 6.302 & \\
\hline Source of Variables & Sum of Squares & Df & Mean square & $\mathrm{F}$ & Sig. \\
\hline Regression & 6.727 & 1 & 6.727 & 0.169 & .681 \\
\hline Residual & 9373.697 & 236 & 39.719 & & \\
\hline Total & 9380.424 & 237 & & & \\
\hline \multirow[t]{2}{*}{ Variables } & Regression weight & & & & \\
\hline & $\mathrm{B}$ & Std error & $\begin{array}{r}\text { Standard. Coef. } \\
(\beta)\end{array}$ & t-value & Sig. \\
\hline (constant) & 13.710 & 2.102 & & 6.522 & .000 \\
\hline Home supportiveness & -0.052 & 0.126 & -0.027 & 0.412 & .681 \\
\hline
\end{tabular}

The result in Table 2 shows that home supportiveness is not a significant predictor of students' performance in French Language. The regression model accounts for only $2.7 \%$ of the variance in students' performance in French Language and this is not a significant fit of the data.

Based on the result, it was revealed that, home supportiveness could not predict students' performance in French Language, looking at the sign of the beta $(\beta=-.027)$, there was negative relationship indicating that as home supportiveness decreases, students' performance in French Language decreases too. Hence, we can conclude 
that, the null hypothesis which states that, home supportiveness does not significantly predict students' performance in French Language be retained.

\section{Discussion of findings}

Findings were discussed under two sub-headings: school supportiveness and students' performance in French Language, and home supportiveness and students' performance in French Language as follows:

\section{- School supportiveness and students' performance in French Language}

The finding of hypothesis one revealed that, school supportiveness significantly predicts students' performance in French Language. This is not strange because aside from linguistic variables that influences performance in Language based subject (of which French Language is one), schools have direct impact on students' performance. For instance, schools without French Language professional teachers are already preparing their students to fail while schools with French Language professional teachers, conducive environment for learning and student support could cause a leap in students' performance.

The findings further supported those of Uba (2012), Cummins, Mirza and Stille (2012) and Agi (2017) whose findings showed that the school and all its properties have a lot to do in relation to performance. The school support a learner enjoys has tremendous effect on the child's academic performance. Schools' friendly environment, classroom setting, belongingness, camaraderie and others are among the constellation factors of school supportiveness associated with academic performance.

- Home supportiveness and students' performance in French Language

The finding of hypothesis two revealed that, home supportiveness does not significantly predict students' performance in French Language. This too was expected because the category of students in public secondary schools are likely from homes with similar socio-economic status and large family size which might impair or hinder adequate support expected from a home towards their wards in respect to their performance in French Language especially when it is not a compulsory subject.

The finding is at variance with Adekola (2008) and Mclntosh (2008), who stated that academic achievements of students are the result of teacher factor. In addition,

The finding of this study also lends credence to Dzever (2015) who maintained that, there is a positive and significant relationship between parenting style and students' academic performance. The agreement of this present finding with the former could be because of location, since parents in this clime seem to exert some level of influence on their wards especially while they are still under their roof, though the influence may drop when they are not living under the same roof. The present finding also supports Ogbemudia and Aiasa (2013) that physical and psychological conditions of the home environment affect the learner academically.

\section{Conclusion}

Based on the findings of this study, the researchers concluded that: School supportiveness as a non-linguistic variable used independently can significantly predict students' performance in French Language, thus the null hypothesis was rejected; while home supportiveness does not significantly predict students' performance in French Language, thus the null hypothesis was retained.

\section{Recommendation}

Based on the findings and conclusion it was recommended the teachers, especially French Language facilitators should be encouraged to engender friendly school environment where learners feel loved and are treated as part of the school in order to keep them happy and free to discuss their academic problems.

\section{References}

Adekola, B. O. (2008). Some predictors of students' achievement in English grammar and comprehension in Ogun State public senior secondary schools. A Ph.D. post-field report presented at the Departmental Seminar of Curriculum Studies an Instructional Technology, Olabisi Onabanjo, University, Ago-Iwoye.

Agbor, C. A. (2001). The influence of teachers' classroom interaction behaviour on students' attitude to French in Calabar Metropolis. M.Ed. Thesis, Faculty of Education, University of Calabar, Nigeria.

Agi, M. S. (2017). Evaluation of primary education curriculum development and implementation processes in Nigeria from 2005-2015. Ph.D. thesis, Institute of Education, University of Ibadan.

Ayeni, E. O. 2012. Factors affecting the learning of French language as a second official language in Obudu Local Government Area of Cross River State. A B.Ed project, faculty of Education, University of Calabar, Calabar - Nigeria.

Castro, O. \& Peck, V. (2005). Learning styles and foreign language learning difficulties. Foreign Language Annals 38(3), 401-409.

Chomsky, N. (2006). Language and mind ( $3^{\text {rd }}$ ed). Cambridge University Press. ISBN 0-521-85819-4

Cummins, J., Mirza, R., \& Stille, S. (2012). English language learners in Canadian schools: Emerging directions 
for school-based policies. TESL Canada Journal 29(6), 25-48.

Dzever, L. T. (2015). The impact of home environment factors on academic performance of senior secondary school students. Bulgarian Journal of Science and Education Policy (BJSEP), 9(4), 47-56.

Eton, I. G. (2015). Teachers' competence and students' academic performance in French language in secondary school in Uyo Local Government Area of Akwa Ibom State. A B.Ed project, faculty of Education, University of Calabar, Calabar - Nigeria.

Federal Republic of Nigeria. (2004). National policy on education. Federal Government of Nigeria $4^{\text {th }}$ Edition, Ministry of Education NERDC Press. Lagos, Nigeria.

Gass, S. M. \& Selinker, L. (2008). Second language acquisition: an introductory course, $3^{\text {rd }}$ Ed. Routledge Taylor and Francis Group, New York. www.ebookstore.tandf.co.uk

Kolawole, O. J. (2015). Problems facing the teaching and learning of French language in college of education in Oyo State. Asia Pacific Journal of Multidisciplinary Research, 3(2), May 2015.

.Li, X., \& Dan R. (2006), Learning question classifiers: The role of semantic information. Natural Language Engineering, 12(3), 229-49. Liang, Han, Harry

McIntosh, J. (2008). Family background, parental involvement, and academic achievement in Canadian schools. J. of Econ Lit. Classification Numbers: 120J62

Ogar, K. N. (2012). Inference and the learning of French Language in Junior secondary schools in Calabar Municipal council area of Cross River State, Nigeria. A B.Ed project, Faculty of Education, University of Calabar.

Ogbemudia, M. I. \& Aiasa, M. V. (2013). Influence of home environment on the academic performance of primary five pupils' in English Language in Orhionmwon Local Government Area of Edo State. Merit Res. J. of Ed. and Rev., 1(5), $120-125$.

Simons, G. F. \& Charles D. F. (eds.). (2018). Ethnologue: Languages of the World, Twentieth-first edition. Dallas, Texas: SIL International. Online version: http://www.ethnologue.com. Copyright (C) 2018 SIL International

Uba, J. E. (2012). School quality variables as determinants of students learning outcomes in Cross River State, Nigeria. M.Ed Thesis, International Centre for Educational Evaluation, Institute of Education, University of Ibadan.

UNESCO, (1996). Global Monitoring Report-EFA by 2015: Will we make it? Oxford: UNESCO. Publishing and Oxford University Press.

Uwatt, L. E (2015). Basic communication and study skills for college and university students. Calabar: Stiffaith Prints and Supplies Co.

Wenden, A. L. (2002). Learner development in language learning. Applied Linguistics.

Wibowo, R. (2001). Language management. New York: Scholastic. 